\title{
Trust and Distrust in M-Commerce: An Integrative Framework
}

\author{
Heda Zhang \\ College of Economics and Management \\ Beijing University of Chemical Technology \\ No. 15 North, Three Ring East Road, Chao Yang District, \\ Beijing, China \\ zhanghd@mail.buct.edu.cn \\ Mengdeer Tuerxunhazi \\ College of Economics and Management \\ Beijing University of Chemical Technology \\ No. 15 North, Three Ring East Road, Chao Yang District, \\ Beijing, China \\ Moldir@mail.buct.edu.cn
}

\author{
Lu Wang \\ College of Economics and Management \\ Beijing University of Chemical Technology \\ No. 15 North, Three Ring East Road, Chao Yang District, \\ Beijing, China \\ 2016200865@mail.buct.edu.cn \\ He Yun \\ College of Economics and \\ Management \\ Beijing University of Chemical \\ Technology \\ No. 15 North, Three Ring East Road, \\ Chao Yang District, Beijing, China \\ yunhe0411@163.com
}

\begin{abstract}
Trust and distrust can coexist and are equally vital in trustor-trustee's relationships by simplifying complexity. In this study, the definitions, roles and relationships of trust and distrust are put forward in the context of mobile commerce. The inherent features of mobile commerce determine that only two psychological states of trust and distrust are not enough to describe the various states of consumers. This paper integrates trust and distrust, and illustrates a framework of four rather than two states of existing and potential $\mathbf{m}$-commerce consumers, which includes high trust \& high distrust, high trust \& low distrust, low trust \& low distrust and low trust \& high distrust. Further, recommendations for $m$-vendors aimed at consumers of each situation are proposed.
\end{abstract}

Keywords-Trust; Distrust; Mobile commerce; Online behavior

\section{INTRODUCTION}

The maturity of mobile technology promotes a boom in mobile commerce. Mobile commerce is a business form integrated by mobile communication devices, combined with wired e-commerce technology and wireless communication network [1]. M-commerce has its inherent features, which can be summed up as "SOLOMOGLO" including social, local, mobile and global. Ubiquity, as the unique feature of $\mathrm{m}$ commerce, makes consumers can purchase anywhere and anytime, which increases trust from consumers to m-vendors. Paradoxically, by increasing the interpersonal distance and instantaneous selection of diversity in m-commerce, distrust exacerbates instead. And critically, in the business environment, distrust always exists, so does in mobile commerce. Thereby, researches on trust, distrust and their relations are equally important in mobile commerce.
Consumer trust under the environment of mobile commerce has been widely studied by scholars. Consumers trust in $\mathrm{m}$ commerce involves trust in technology and consumer-business relationships issues. As mobile technology matures, the focus is transferred from technology to consumer-business relationships issues, especially the trust relationship between consumers and m-vendors [2-5]. Shao et al. (2009) verify that responsiveness and brand image of the vendors' quality has a significant impact on consumers' satisfaction and trust towards mobile commerce [2]. From the perspective of trust life-cycle, Xiao Bingguo (2013)'s research indicates that service characteristics of m-vendors plays an important role in trust building, maintenance, dispelling and repairing [3]. Li (2013) highlights that consumers' perceived reputation of vendors is an essential dimension and related to trusting beliefs towards vendors in tourism industry in m-commerce [4]. Hassan et al. (2017) consider that the information quality which has a significant impact on initial trust building reflects the ability and benevolence of service providers [5]. However, compared with various researches of trust, distrust and the qualities of relations between trust and distrust have not been explained in the context of m-commerce.

The viewpoint of coexistence and separation of trust and distrust has been adopted by complicating the relationship between trustor and trustee [6-7]. Benamati et al. (2007) illustrate that users may trust that banks can help them manage their saving accounts, but they do not trust that banks can help them make a good investment in online banking [7]. The phenomenon of coexistence and separation of trust and distrust also exists in m-commerce. For instance, consumers trust the m-vendor to make a quick order but they distrust that the delivery will arrive on time. Hence, based on the inherent features of m-commerce and a delicate tension of trust and distrust, only trust and distrust are inadequate to explain the 
state of consumers. By integrating trust and distrust, there will be more psychological states of consumers that need to be explored.

This study focuses on the trusting and distrusting nature and qualities of the relations between consumers and $\mathrm{m}$ vendors. The concept of trust and distrust and the relations between them are discussed in the context of m-commerce. Based on the interaction and interdependence of trust and distrust, a framework is shown to reflect the psychological states of consumers and then appropriate strategies for $\mathrm{m}$ vendors are proposed aimed at consumers in each state.

\section{TRUST, DistruST AND RELATIONSHIP BETWEEN TRUST AND DISTRUST IN M-COMMERCE}

\section{A. The Nature of Trust and Distrust in M-Commerce}

Trust is vital to m-commerce to simplify complexity by instilling cooperative actions to attain desirable outcomes. Mayer et al. (1995) propose the definition of trust within organizations; they view that trust is formed when a trustor displays a willingness to be vulnerable to the trustee based on the expectation that the trustee will perform as desired by the trustor [8]. M-technology enables consumers to obtain massive information of products or services on line and then trade with $\mathrm{m}$-vendors at anytime and anywhere. For consumers, when they purchase a product in $\mathrm{m}$-commerce, they scan the specific information of the product described by different m-vendors easily due to the instantaneous selection of diversity in $\mathrm{m}$ commerce. Consumers may make comparison among different $\mathrm{m}$-vendors and finally choose the vendor whom they think is the most trustworthy. To be specific, consumers perceive the trustworthiness (deconstructed as integrity, benevolence and ability by Mayer et al. (1995)) and identify subjectively which $\mathrm{m}$-vendor is the best to be able to fulfill the commitment. Thus, trust in $\mathrm{m}$-commerce is defined as a perception about integrity, benevolence and ability of m-vendors and their conducts of fulfilling the commitment.

Distrust must be acknowledged which functions equally as trust by simplifying complexity; distrust simplifies complexity by avoiding tasks or instilling protective actions when facing potentially injury. Distrust in interpersonal relationship can be described in terms of confident negative expectations regarding another's conducts [6]. In the context of e-commerce, distrust is defined as the internet vendor's motives, intentions and behaviors which are sinister and harmful to the internet shopper's interests [9-11]. Distrust does not mean lack of trust, but it is a warning of individual's interests damaged by others [12]. Consumers may be more susceptible to fraud due to the virtual transactions of a separation of time and space in $\mathrm{m}$ commerce. Fake and other forms of $\mathrm{m}$-commerce fraud have taken place frequently in recent years. Moreover, instantaneous selection of diversity in $\mathrm{m}$-commerce may aggravate distrust. Distrust, as the opposite concept of trust, is also a perception that consumers can not reach trustworthiness towards $\mathrm{m}$ vendors who do not behave in the manners of integrity, benevolence or ability.

\section{B. The Relationship Between Trust and Distrust in M- commerce}

The relationship between trust and distrust varies from single-factor view to two-factor view. The early studies regard trust and distrust as a single dimensional bipolar concept. One end is complete trust, and the other end is complete distrust. Trust and distrust do not exist simultaneously [13]. Lewicki et al. (1998) explain that the interpersonal relationship is multiple, when individuals interact with others, they can not only realize the trustworthy aspects of others, but also discover others' untrustworthy aspects [6]. Furthermore, based on Herzberg's theory [14], they also discuss the separation of trust and distrust Low trust is not the same thing as high distrust, and high trust is not the same thing as low distrust. Simultaneous and separated trust and distrust reflect the complexities that arise in interpersonal relationship by integrating both positive and negative perceptions. The viewpoint of coexistence and separation of trust and distrust has been applied in e-commerce transaction situation [7, 9-11]. In online banking, users may trust that banks to do "the right thing" with their money, but still verify that transactions are posted correctly. Besides, the coexistence of trust and distrust represents a healthy relationship between consumers and online banking [7]. Carol et al. (2009) conclude that trust and distrust can coexist by an interview with the perception of two retail websites selling electronic products [9]. The view of coexistence and separation of trust and distrust is also applicable to mobile commerce. Consumers trust that the m-vendor can do "the right thing" for them during the process of the purchase (quick ordering or the third party payment guaranteed), but they still distrust the mvendor in other aspects (the quality of products or delivery on time). Therefore, it is clear that trust and distrust are coexisting and separated in the context of mobile commerce.

\section{THE FRAMEWORK OF TRUST AND DISTRUST IN M- COMMERCE}

The simultaneous effect of trust and distrust has been accepted in interpersonal relationship, e-commerce field and other complex social contexts. In the situation of m-commerce, only trust and distrust are inadequate to describe the relationship between consumers and m-vendors. Due to the coexistence and separation view of trust and distrust, the relationship between consumers and $\mathrm{m}$-vendors is complex by integrating trust and distrust. Therefore, the framework of trust and distrust is established in the condition of m-commerce which is composed of high trust, low trust, high distrust and low distrust in this paper. Compared with the attributes of trust and distrust in Lewicki's research within organizations, trust and distrust have their own characteristics in m-commerce. In the aspect of trust, due to the instantaneous selection of diversity in $\mathrm{m}$-commerce, consumers may not have strong faith to m-vendors. What's more, due to the supervision of third party payments, consumers may perceive security and reliability when they trade with $\mathrm{m}$-vendors involved money. In the aspect of distrust, service failure of $m$-vendors just makes consumers consider that m-vendors lack integrity, benevolence or ability. Consumers will only feel skeptical and wary, but are not fear of m-vendors or do not express cynicism to m-vendors. Hence, high trust in m-commerce is characterized by safety, 
reliability, confidence, assurance and initiative. Low trust is absence of safety, absence of reliability, absence of confidence, apprehension and hesitance. High distrust in $\mathrm{m}$-commerce is characterized by skepticism, wariness and vigilance. Low distrust is absence of skepticism, absence of wariness and absence of vigilance (see Table 1).

TABLE I. INTEGRATING TRUST AND Distrust IN M-COMMERCE CONSUMERS

\begin{tabular}{|c|c|c|c|}
\hline & $\begin{array}{c}\text { High Distrust } \\
\text { Skepticism, Wariness, Vigilance }\end{array}$ & & $\begin{array}{c}\text { Low Distrust } \\
\text { Absence of skepticism, Absence of wariness, } \\
\text { Absence of vigilance }\end{array}$ \\
\hline \multirow[t]{2}{*}{$\begin{array}{l}\text { High Trust } \\
\text { Characterized by } \\
\text { Safety } \\
\text { Reliability } \\
\text { Confidence } \\
\text { Assurance } \\
\text { Initiative }\end{array}$} & \begin{tabular}{ll} 
& \multicolumn{1}{c}{ Ambivalence } \\
- & Trust but verify \\
- & Distrust but satisfy \\
- & Relationships highly segmented and bounded \\
\end{tabular} & & $\begin{array}{l}\quad \text { Calculative Trust } \\
\text { - } \quad \text { High demand-supply matching } \\
\text { - } \quad \text { Interdependence promoted } \\
\text { - } \quad \text { Opw initiatives } \\
\end{array}$ \\
\hline & & 1 & 2 \\
\hline $\begin{array}{c}\text { Low Trust } \\
\text { Characterized by } \\
\text { Absence of safety } \\
\text { Absence of reliability } \\
\text { Absence of confidence } \\
\text { Apprehension } \\
\text { Hesitance }\end{array}$ & \begin{tabular}{ll} 
& \multicolumn{1}{c}{ Violated Trust } \\
- & Harmful motives assumed \\
$-\quad$ Undesirable eventualities expected \\
$-\quad$ Interaction occurs only as required \\
- & Opporchase \\
& Opportunities pursued to repair trust
\end{tabular} & 4 & \begin{tabular}{ll}
3 & \multicolumn{1}{c}{ Initial Trust } \\
& Lack of trustworthiness/untrustworthiness \\
- & Limecific perception \\
- & Possible purchase \\
- Opportunities pursued to build trust
\end{tabular} \\
\hline
\end{tabular}

In accordance of the above description, four components of the framework in m-commerce consumers are high trust \& high distrust, high trust $\&$ low distrust, low trust $\&$ low distrust and low trust \& high distrust. Every psychological state of the consumer and suggestions towards m-vendors will be discussed in detail in following subsections.

\section{A. High Trust and High Distrust: The Ambivalent Consumer (Cell 1)}

As illustrated in cell 1 , the ambivalence is the result of coexistence of high trust and high distrust. Within mcommerce context, consumers may have confidence in $\mathrm{m}$ vendors in some aspects, meanwhile they are wary about mvendors in other aspects. For instance, consumers trust that mvendors are able to make orders quickly for them, while consumers also may have a suspicion that products they actually receive are not exactly the same as displayed on line by m-vendors. The coexisting presence of high trust and high distrust represents an ambivalent relationship between consumers and m-vendors, which can lead to a delicate tension that makes consumers keep rational attitude towards m-vendors. But unlike the condition of low trust \& high distrust, the competing trust and distrust make these consumers tend to be highly segmented in their beliefs regarding m-vendors. Hence, for $\mathrm{m}$-vendors, they should perceive and react immediately to such consumers' conflicting feelings and make effective efforts (e.g., quick and friendly communications) to reinforce consumers' trust in order to stimulate consumers to purchase quickly.

\section{B. High Trust and Low Distrust: The Easily Lost Consumer (Cell 2)}

Under the condition of high trust and low distrust in cell 2, consumers are almost completely trust in m-vendors; it means that consumers perceive $\mathrm{m}$-vendors have enough integrity, benevolence and ability to fulfill the commitment and therefore it seems that there is absence of excuse to distrust. Rather, as mentioned above, distrust is always inevitable in mobile commerce whether more or less. Further, owing to the instantaneous selection of diversity in $\mathrm{m}$-commerce, a product can be compared and purchased from different m-vendors anywhere and anytime; consumers compare all aspects of products conveniently and finally choose the product which is perceived worthy of being purchased. Hence, consumers' trust in m-commerce builds on maximizing the interests of consumers. Even if in high trust state there still exists low distrust, namely, calculative trust. Additionally, the instantaneous selection of diversity makes trust exist temporarily during the purchasing activities of consumers, so they neither have formed brand loyalty as in traditional commerce, nor have formed a strong habit as using ecommerce. For m-vendors, they should keep cautionary eyes 
on these easily lost consumers who are in the state of high trust and low distrust (calculative trust). Measures such as individualized attentions or connections (mails or messages) with appropriate frequency are also necessary in order to maintain consumers' trust.

\section{Low Trust and Low Distrust: The Prospective Consumer (Cell 3)}

Low trust \& low distrust labeled "initial" trust" in cell 3 is the condition that consumers neither judge trust nor distrust towards m-vendors due to the lack of perceptions of trustworthiness and untrustworthiness. A similar phenomenon occurs in $\mathrm{m}$-commerce when consumers trade with a new $\mathrm{m}$ vendor with the low level of both trust and distrust as a building of initial trust. Another phenomenon is that when there is no purchase between a consumer and his or she once trusted m-vendor for a long time, thus resulting in the consumer' trust oblivion, which also needs the building of initial trust. Consumers in the state of initial trust do not have enough understandings towards $\mathrm{m}$-vendors, nevertheless, purchases still may happen if consumers' demands are urgent. Hence, consumers of low trust and low distrust state should be viewed as prospective consumers who are worthy of being developed or aroused by m-vendors. Some important factors containing good communication, user interface design, quick response speed and other factors to gain trust should be guaranteed by m-vendors in order to win initial trust. For consumers who are in the state of trust oblivion, arousing measures including some affective connections or price promotion inducement may be taken by m-vendors.

\section{Low Trust and High Distrust: The Distrustful Consumer's Trust Repair (Cell 4)}

Low trust \& high distrust called as "violated trust" represents a state that consumers have little reasons for confidence in m-vendors and sufficient reasons for skepticism and wariness, which is common in m-commerce when service failure occurs. At this time, consumers' distrust increases meanwhile trust erodes sharply. The condition of violated trust makes it extremely difficult to maintain interdependence relations precisely because both interests and emotions of consumers are hurt by m-vendors [6]. For consumers, they may restrainedly dispose the interaction and take defensive actions towards m-vendors. Certainly, transaction relations between consumers and m-vendors will be terminated and communications with m-vendors are cautious and guarded during the problem-solving process. For m-vendors, they should contact consumers in the first time and take effective trust-repaired measures aimed at different types of service failure (e.g., third party logistics, insufficient ability or conscientiousness of m-vendors) to remedy interests and emotions of consumers.

\section{CONCLUSION}

Trust and distrust function equally by simplifying complexity in m-commerce context. In this paper, the trusting and distrusting definitions and qualities of the relations between consumers and $\mathrm{m}$-vendors are presented. Based on the separated yet related constructs between trust and distrust, the framework consisted of four psychological states is established including high trust $\&$ high distrust, high trust \& low distrust, low trust \& low distrust and low trust \& high distrust, which are marked sequentially as "Ambivalence", "Calculative Trust", "Initial Trust" and "Violated Trust". Additionally, four conditions of the consumer are labeled as "The Ambivalent Consumer", "The Easily Lost Consumer", "The Prospective Consumer" and "The Distrustful Consumer's Trust Repair" to reflect each state of the consumer. To conclude, appropriate strategies for $\mathrm{m}$-vendors to each state of consumers are proposed.

\section{ACKNOWLEDGMENT}

The authors acknowledge the financial supports from the National Natural Science Foundation of China (Grant no. 71401005) and Fundamental Research Funds for the Central Universities (Grant no. PTRW1703).

\section{REFERENCES}

[1] Siau Keng, Lim Ee-Peng, and Shen ZiXing. 2001. Mobile Commerce: Promise, Challenges, and Research Agenda. Journal of Database Management, 12(3): 4-13.

[2] Yung Shao Yeh, and Yung-Ming Li. 2009. Building Trust in MCommerce: Contributions from Quality and Satisfaction. Online Information Review, 33(6): 1066-1086.

[3] Xiao Bingguo. 2013. Research on Dynamic Management of MC Trust Resources. Central South University, Changsha, Hunan Province, China. (In Chinese)

[4] Li, W. 2013. Dimensions of Trust in Tourism M-commerce: a Conceptual Model. Information Technology Journal, 12(15): 3279-3283.

[5] Hassan Ahmed Hassan, Manna Ruba Faisal and El-Ebiary Yousef. 2017. The Effect of Trust Based Factors on Using Mobile Commerce in Jordan. International Journal of Contemporary Computer Research, 1(2): 1-7.

[6] Lewicki Roy J., and Mcallister Daniel J. 1998. Trust and Distrust: New Relationships and Realities. Academy of Management, 23(3): 438-458.

[7] Benamati J. S., and Serva Mark A. 2007. Trust and Distrust in Online Banking: Their Role in Developing Countries. Information Technology for Development, 13(2): 161-175.

[8] Mayer, R.C., Davis, J. H., and Schoorman, F. D. 1995.An Integrative Model of Organizational Trust. Academy of Management Review, 20(3) 709-734.

[9] Carol X O, and Choon L S. 2009. To Trust or To Distrust, That is the Question- Investigating the Trust-Distrust Paradox. Communications of the ACM, 52(5): 135-139.

[10] McKnight, D. H., Kacmar, C., and Choudhury, V. 2001. While Trust is Cool and Collected, Distrust is Fiery and Frenzied: A Model of Distrust Concepts. Americas Conference on Information Systems, 883-888.

[11] McKnight, D. Harrison, Kacmar, Charles J., and Choudhury Vivek. 2004. Dispositional Trust and Distrust Distinctions in Predicting Highand Low-Risk Internet Expert Advice Site Perceptions. E-Service Journal, 3(2): 35-58.

[12] Cho J. 2006. The Mechanism of Trust and Distrust Formation and Their Relational Outcomes. Journal of Retailing, 82(1): 25-35.

[13] Baier A. 1986. Trust and Antitrust. Ethics, 96(2): 231-260.

[14] Herzberg, F., Mausner, B., and Snyderman, B. B., 1967. The Motivation to Work 2nd ed. John Wiley and Sons, Ltd., NY, USA 